THE MECHANISM OF THE DEVELOPMENT OF NONBACTERIAL, CHRONIC CARDIOVALVULAR DISEASE *

\author{
WILLIAM THALHIMER, M.D. \\ MILWAUKEE
}

A fairly complete search through the literature reveals no accurate knowledge or satisfactory explanation of the pathologic process which is the basis of the progressive development of chronic cardiovalvular disease. By chronic cardiovalvular disease is meant a chronic, nonbacterial, nonrheumatic disease of a heart valve, or of valves, which is characterized at the necropsy by marked fibrosis of the valve cusps or flaps sometimes causing marked distortion or stenosis, at times with calcareous cleposit in the valves, but unaccompanied by vegetations other than very small ones, such as are described in this paper.

The histologic changes in simple or verrucous endocarditis are well known, as are those of the terminal stage of the process which is usually, through improperly, termed "chronic endocarditis." The cause of the progressive changes in nonbacterial lesions of the heart valve, and the mechanism of these changes, is very imperfectly understood.

It will be necessary, before taking up this problem, to discuss the terminology and classification of acute and chronic diseases of the heart valves. Many of the older terms given to different types of cardiac disease have been found inappropriate in the light of recent knowledge. Many cases have erroneously been termed acute endocarditis where there was no acute inflammation of the endocardium. The term, however, which probably has been most abused is "chronic" endocarditis. This term should be discarded, as there is in all probability no disease of the heart valve which can be described as a "chronic" inflammation. The only conditions that should be termed endocarditis are those which are inflammatory in nature, and in which the etiology of the inflammatory lesion of the endocardium is known. These are bacterial, rheumatic and syphilitic endocarditis. As Libman suggests, the organism causing the bacterial endocarditis should always be included in the name of the lesion; such as "acute Staphylococcus aureus endocarditis."

In the same way, "chronic myocarditis" is usually improperly applied. Chronic inflammation of the myocardium is very rare, indeed. Most cases termed "chronic myocarditis" are conditions entirely different from this, such as myocardial weakness, interestitial fibrosis of the myocardium, either localized or diffuse, coronary artery disease, etc.

* From the Laboratories of Columbia Hospital. 
Libman ${ }^{1}$ differentiates sharply between cases of valvular defect alone and cases of endocarditis occurring with or without a previous valvular disease. He describes a valvular defect as "a direct result of a previous disease process of the valve." The important point to be made clear is that a valvular defect is the result, or sometimes the end stage, of disease of a heart valve, and cannot, in any sense, be termed an endocarditis, acute or chronic. Libman tabulates the causes of valvular defects as follows:

1. Rheumatic endocarditis.

2. Syphilitic endocarditis.

3. Atherosclerosis.

4. Congenital defects.

5. Traumatic lesions.

6. A previous bacterial infection, with recovery.

He classifies the varieties of "endocarditis" (not valcular defects) as follows:

1. Rheumatic.

2. Syphilitic.

3. Bacterial.

4. Terminal (verrucous).

5. Indeterminate.

This terminology and classification is considered the best yet suggested. It is believed, however, that the term "endocarditis" should be eliminated entirely, and, in its place, the conditions should be termed acute or chronic cardiovalvular disease. It is probably too much to expect that the term endocarditis will be given up, but it seems certain that the term chronic endocarditis will be dropped. The term endocarditis is used herewith in connection with rheumatic fever and bacterial valvular disease, in order to conform with the present accepted terminology.

We are not concerned in this paper with bacterial infections of the endocardium, whether they are acute or subacute, or, as the latter is sometimes termed, chronic malignant endocarditis. These conditions have been described well by Schottmueller, Horder, Osler, Libman, Rosenow and others. The mechanism of the development of these lesions is also well understood, whether considered as starting from a bacterial embolus in the valve, or whether they start from bacterial implantation on the valve. Some phases of this mechanism, however, will be discussed later, as they have a bearing on the mechanism of the development of chronic cardiovalvular disease.

1. Libman, E.: A Study of the Endocardial Lesions of Subacute Bacterial Endocarditis, Am. J. M. Sc. 144:313, 1912. The Clinical Features of Cases of Subacute Bacterial Endocarditis That Have Spontaneously Become BacteriaFree, Am. J. M. Sc. 146:625. 1913. Some General Considerations Concerning Affections of the Valves of the Heart. (Clinic of Dr. E. Libman. Mount Sinai Hospital, New York.) 


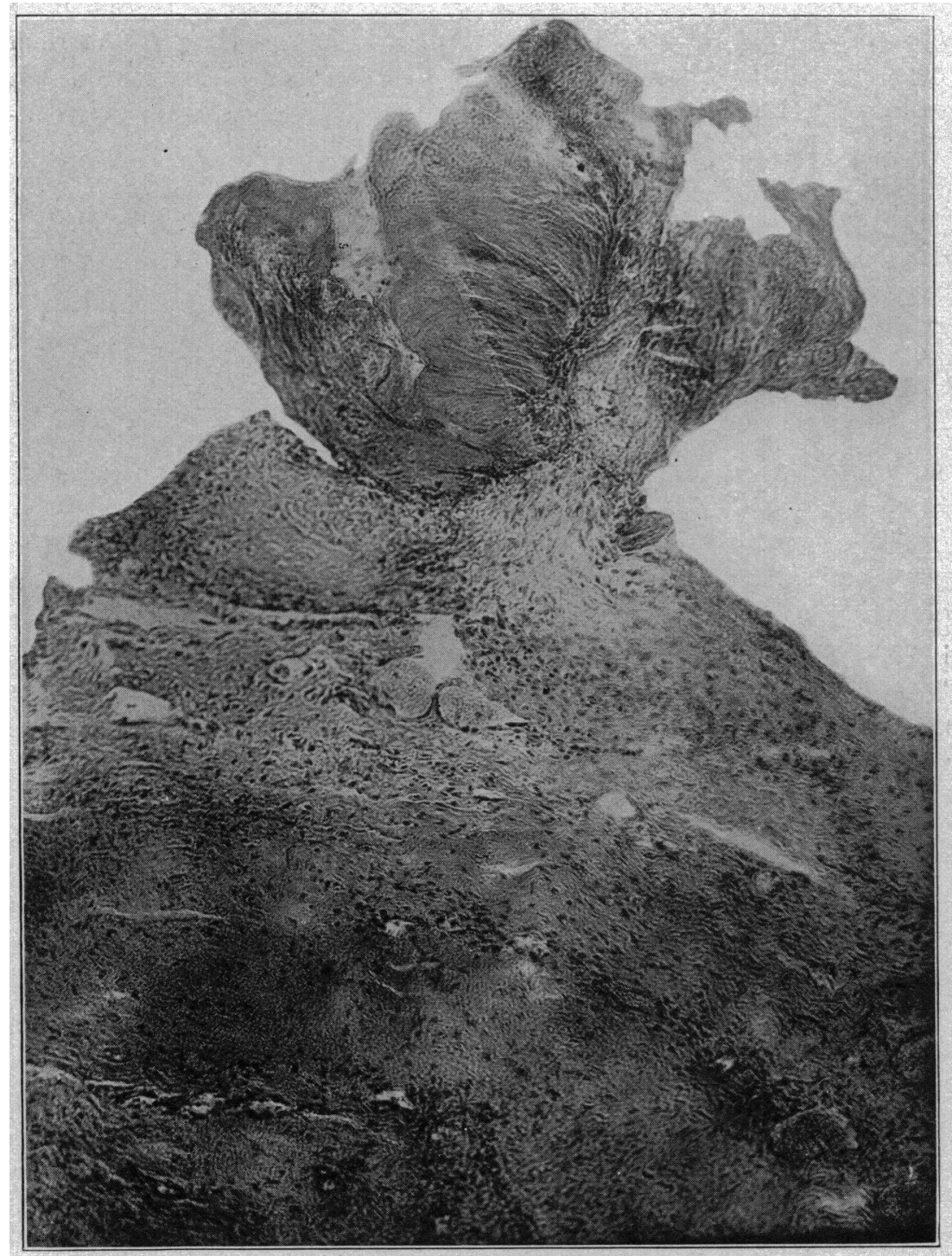

Fig. 1.-Verruca on mitral valve in a case of acute rheumatic fever, showing beginning organization of hyaline thrombus deposit and reaction in valve beneath. 
Our problem narrows itself to this: in what manner do chronic nonbacterial diseases of the heart develop, and what is the pathology and histology of this process? It is believed that the clue to the solution of this problem is to be found in the correlation of the results of the study of certain small excrescences found in a number of abnormal or diseased conditions of the heart at different locations on the endocardium, but most often on the valves. These conditions are congenital cardiac disease, so-called simple or verrucous endocarditis of rheumatic fever, so-called terminal verrucous endocarditis, and verrucous endocarditis in practically all cases of chronic cardiovalvular disease. These will have to be described separately, and it is also necessary to discuss bacterial endocarditis.

\section{VARIETIES OF ENDOCARDITIS}

Bacterial Endocarditis.-The macroscopic and microscopic characteristics of bacterial endocarditis are well known and need no further description. Reference can be made, in particular, to the articles of Libman. ${ }^{1}$

The vegetations, except in acute fulminating cases, are comparatively large and rough, being warty or cauliflower-like in appearance, or occurring as even larger, irregular masses. In cases such as acute pneumococcus endocarditis complicating a pneumonia, the vegetations may occasionally be small and beaded, smooth and glistening. The organism causing the lesion always can be demonstrated readily, however, in either smear, culture or section, thereby differentiating these cases from the verruca of acute rheumatic endocarditis.

In only a single group of bacterial endocarditis cases, namely, the bacteria free cases of subacute bacterial endocarditis, as described by Libman, are no bacteria found in the vegetations. Nevertheless, there can be no doubt that Libman has demonstrated that bacteria caused the lesions and these subsequently become bacteria free.

Bacterial vegetations are always friable, unless calcified, and even then, they are usually friable. They are made up of masses of blood platelet thrombus, mixed thrombus, bacteria scattered or in masses, and also sometimes of calcareous deposit. Degeneration or necrosis of the thrombus material often occurs. Organization takes place only to a slight or moderate extent at the base of the vegetation, except in Libman's bacteria free cases, where it may extend throughout the vegetation. In all other bacterial cases the surface of the vegetations is not covered by endothelium and it is usually not covered even in the bacteria free cases. Bacteria growing in the thrombus form almost the entire surface layer but the bacteria may also be found far beneath the surface.

Occasionally small beaded vegetations occur alongside of large ones in subacute bacterial endocarditis, which, if alone, might be confused 


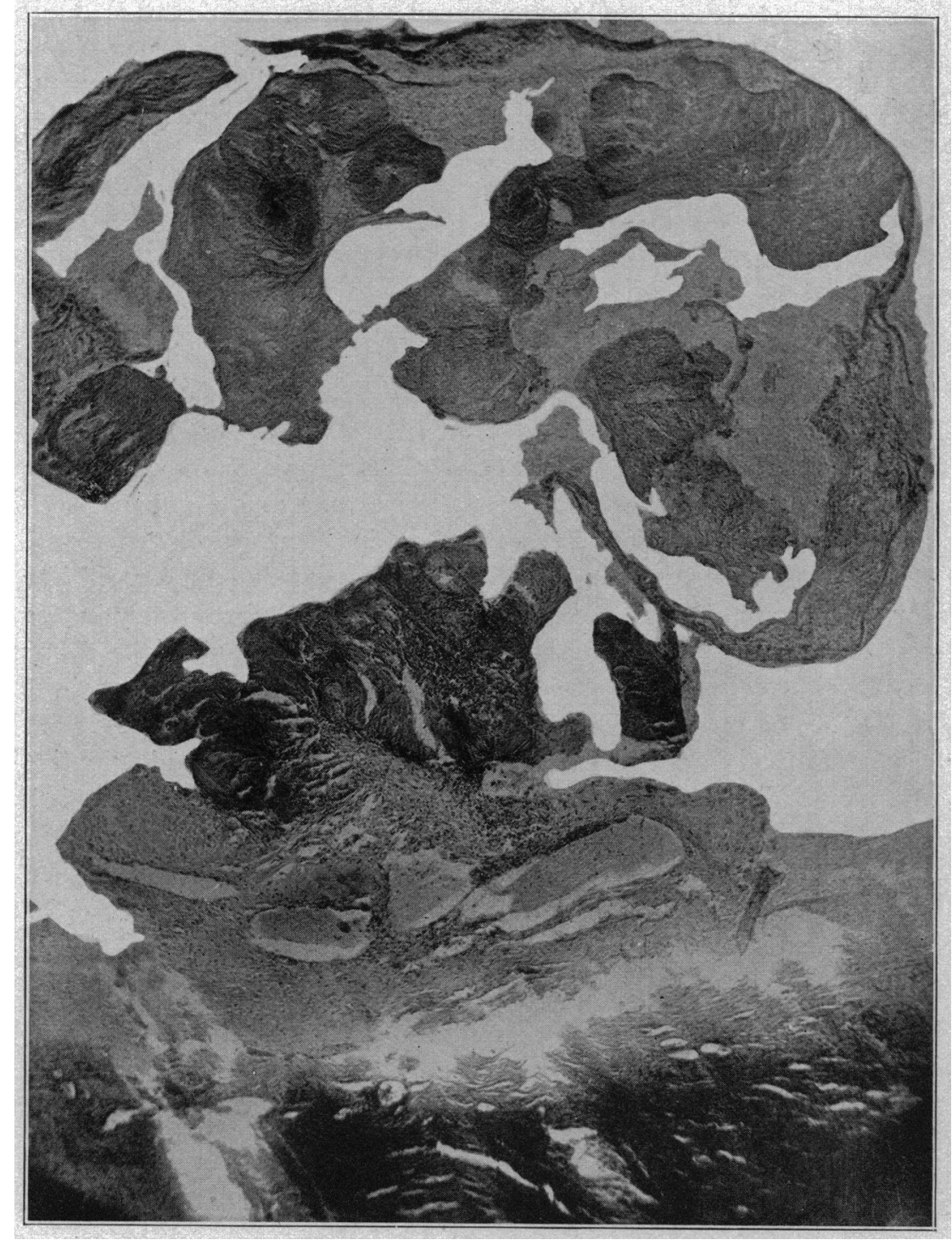

Fig. 2. - Verruca on mitral valve in a case of acute rheumatic fever. Larger than the one shown in Figure 1. 
macroscopically with acute rheumatic endocarditis. Microscopically, they are easily differentiated, as they always contain bacteria. Bacterial vegetations, therefore, are merely infected thrombi on the valves.

Simple or Verrucous Endocarditis of Rheumatic Fever.-This condition is so well described by Aschoff in his textbook on Pathology, that only the necessities of this article justify personal observations of this lesion. This lesion is distinctive. The gross lesion is sufficiently characteristic so that acute rheumatic fever, or one of its associated conditions (such as chorea), can be diagnosed in practically every case in which this lesion is found. In a few hearts lesions have been observed that were so similar to those of verrucous rheumatic endocarditis that macroscopically it could not be decided definitely whether they were the lesions of rheumatic fever. In all of these cases, when a positive opinion could not be formed, subsequent study of the heart failed to reveal Aschoff bodies, which are the specific, microscopic, myocardial lesions of acute rheumatic fever and its allied conditions. In all hearts which were macroscopically regarded as representing a verrucous endocarditis of rheumatic fever, Aschoff bodies were found in the myocardium.

Rheumatic verrucous endocarditis appears grossly as a beaded line along the line of closure of the various valves. These beads vary in size from being barely visible to 2 or $3 \mathrm{~mm}$. in both width and height. They may be either discrete or fused. When fused they form a continuous line on one or more of the valve flaps or cusps. When the beads are very small they give the line of closure of the valve a sandpaper-like appearance. The lesions are either colorless, or grayish white, rounded, smooth and glistening. They are never pedunculated but are always sessile. The verruæ are rather firm and tough, are not easily broken off from the valve and when picked off, a small portion of the superficial tissue of the valve invariably comes off with them.

Microscopic Appearance: The minute, beaded vegetations are composed entirely of an organizing, hyaline thrombus. The connective tissue immediately beneath the endocardium furnishes fibroblasts through which the thrombus becomes organized. The process of organization can, therefore, be regarded as beginning in these tissue cells. This area of actively growing connective tissue cells has all the characteristics of growing connective tissue elsewhere. More plasma is present between these cells than is found elsewhere in the valve. The valve about the base of the thrombus and, at times, the tissue throughout the valve, shows an inflammatory process. This process is an infiltration with mononuclear leukocytes, occasional plasma cells and polymorphonuclear leukocytes. The endothelium on either side of the thrombus, where it arises from the endocardium, shows a condition of active growth. There is apparently an effort on the part of the endothelium to 


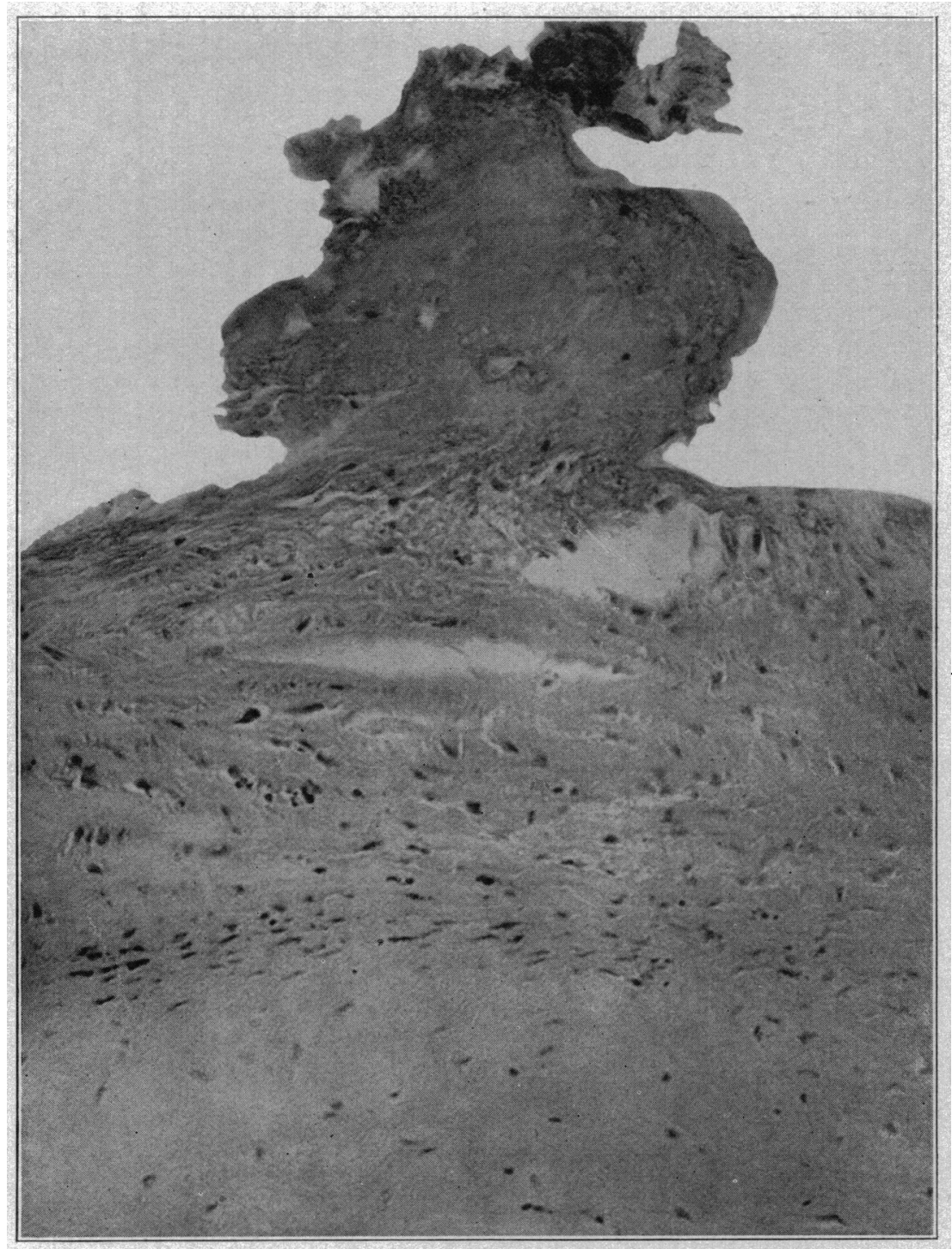

Fig. 3.-Terminal verrucous endocarditis; mitral valve; no organization of hyaline thrombus deposit and no reaction in the valve heneath it. 
grow up over the thrombus. This new endothelium usually extends up on either side to a distance of from one-fourth to one-third of the surface of the thrombus. The verrucæ in the acute stage are infrequently completely covered by endothelium, though this always occurs with the older lesions. This observation is at variance with that of Libman, who claims that the endothelium rapidly grows over and completely covers the small verrucous vegetations.

In different vegetations may be observed varying numbers of hyaline thrombi encroached on by granulation tissue. Growing into the thrombus from its base, and from its side, the fibroblasts then attack these islands from their entire periphery and eventually convert them into a ball or whorl of granulation tissues, which become incorporated in the valve. This has an important bearing on observations which will be reported on later.

A careful search has been made by Rothschild and Thalhimer for bacteria and protozoa in the vegetations and myocardium in many cases of acute rheumatic fever. In no instance were any bacteria or protozoa found. It may also be stated here that no organisms were ever found in Aschoff bodies. This observation is of importance in relation to the contention of some authors that rheumatic fever is caused by a special type of streptococcus.

It could not be determined positively whether the minute thrombi of the vegetations were secondary to a lesion of the endothelial layer of the endocardium, or of the subendothelial layer. Beneath the very small lesions changes are present only in the most superficial layer of the endocardium. These changes are so superficial that they seem to indicate that the primary lesions are essentially endothelial and not subendotheiial.

It is of interest to note that Aschoff bodies, ${ }^{2}$ or Aschoff cells, were never found in the vegetations, in their base or in the valves. Attention should be called to the fact that emboli never arises from the vegetations in cases of acute rheumatic endocarditis, since the vegetations are never friable enough to break and form emboli. Where embolic phenomena occur in this condition the emboli must arise from thrombi situated elsewhere than on the heart valves, such as from an auricular thrombus.

Terminal Verrucous "Endocarditis."-Terminal verrucous "endocarditis" occurs in patients who die after a long, slowly progressing illness, such as carcinoma, tuberculosis, etc.

2. In a study made by Rothschild and myself (Rothschild, M. A., and Thalhimer, W.: On the Significance of the Sub-Miliary Myocardial Nodules of Aschoff in Rheumatic Fever, J. Exper. M. 19:417, 1914), a very careful search was made in the valves of rheumatic hearts for Aschoff bodies. We were, and are still, at a loss to explain their absence here and their presence in the specific lesions of the myocardium. 


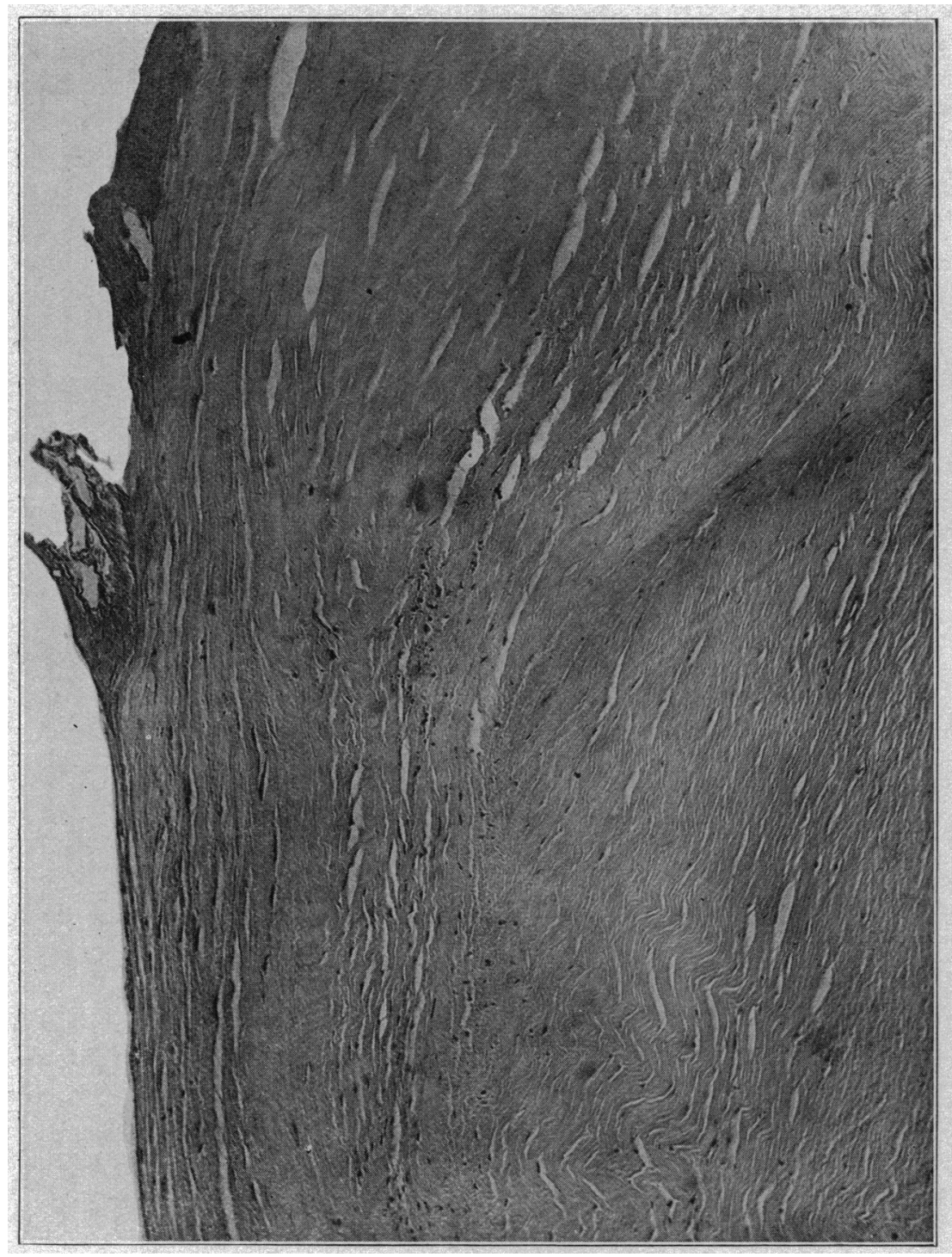

Fig. 4.-Terminal verrucons endocarditis: Hat hyaline thrombus deposit on aortic valve. No organization of thrombus or reaction in the ralve heneath it. 
There are present upon the heart valves of many of these cases very minute, colorless or gray, rounded, glistening, firm verrucæ. They are usually smaller than those in rheumatic fever, fewer in number, scattered, and never form a continuous beaded line.

Microscopically these terminal verrucæ have identically the same structure as those caused by rheumatic fever, but there is no inflammatory reaction in the valve, either near the verruca or elsewhere. The small vegetations are formed entirely of hyaline thrombi, usually bare, but sometimes covered partially or even completely by endothelium. Either no organization of this thrombus is present, or practically none. There is no change in the valve beneath the verrucæ which is in any way related to the process on the surface of the valve. The small vegetative lesions have all the appearances of a recent process, without any accompanying inflammatory changes and with only proliferative changes in the heart valve.

A Special Type of Verrucous Endocarditis Found on the Valves of Nonbacterial, Nourheumatic Chronic Cardiovalvular Disease.-Verrucous "endocarditis" in chronic cardiovalvular disease is believed to be of common occurrence and yet seems to have been either comparatively unnoticed, or regarded as unimportant. I call attention to these lesions in the hope that others will verify the fact of their common occurrence and of certain structural valve changes associated with them.

On practically all thickened, fibrosed valves, careful inspection will reveal the presence of few or many minute verrucæ, grossly and microscopically similar in appearance to the very small lesions of terminal verrucous endocarditis. They are specially common on valves presenting marked stenosis, such as "buttonhole" mitral stenosis. In these extreme degrees of valvular defect the valve flaps are greatly thickened, very fibrous, usually uneven and often infiltrated with small or large amounts of calcium. Very often one or both places of junction of the two mitral flaps have a superficial, or deep, cracklike defect, which has somewhat the appearance of an ulcer. These cracks are at the ends of the "buttonhole" opening in the valve. The edge of these ulcer-like lesions is firm, irregular and slightly raised. The bases are rough and dull in appearance, as though composed of poorly nourished or degenerative tissues. On or near the edge of the cracks, as well as on the rounded valve edges, are found a few, or many small verrucæ. These verrucous lesions in their macroscopic and miscroscopic appearance resemble both rheumatic endocardial verrcucæ and terminal endocardial verrucæ, and have some of the characteristics of both. They are generally larger than the terminal, but not as large as the rheumatic lesions. They also are composed of hyaline thrombi, usually bare, but sometimes covered by endothelium. They show different degrees of 


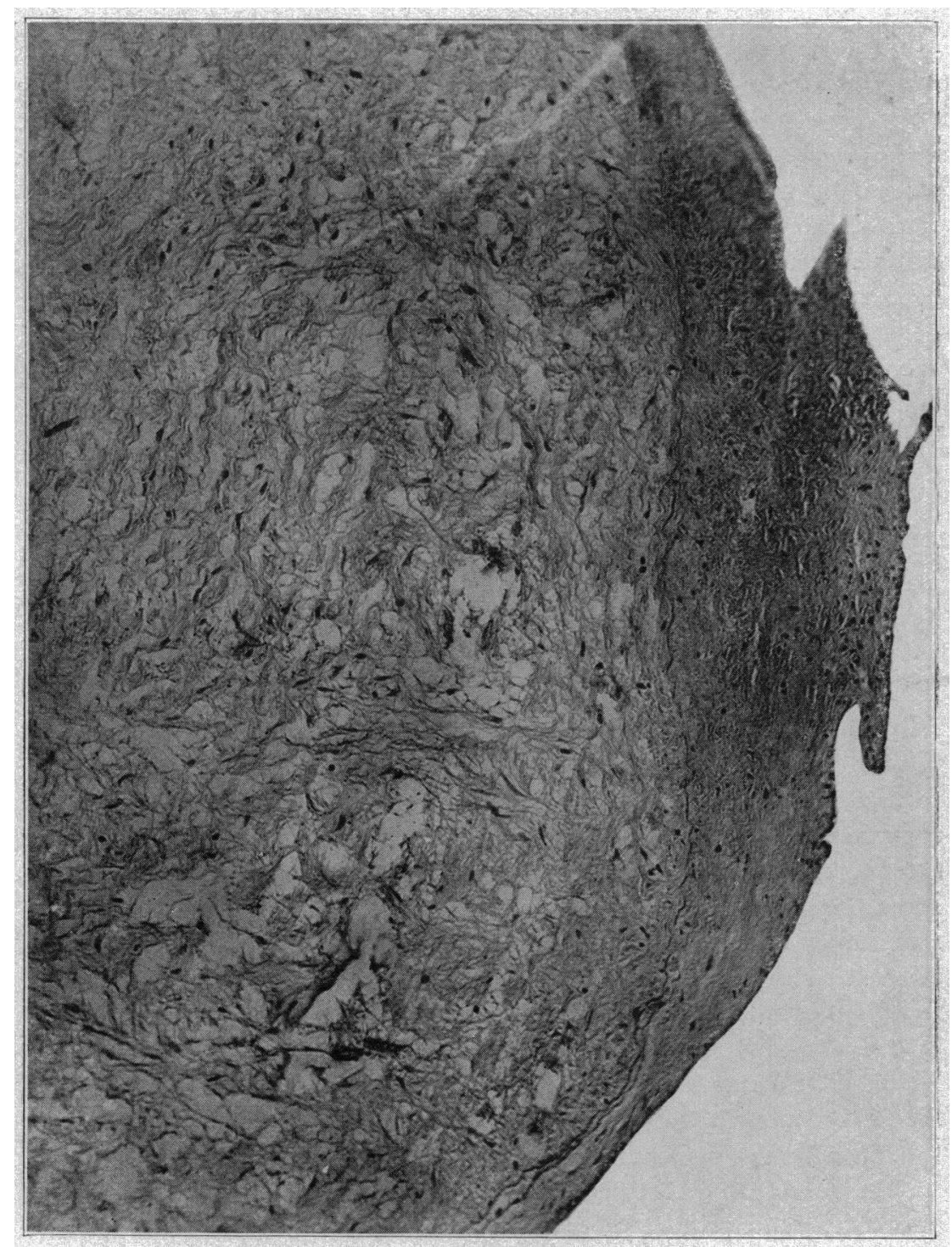

Fig. 5.-Small flat verruca on mitral valve in a case of chronic cardiovalvular disease. Organization is occurring and fibroblasts are scattered throughout the hyaline thromlus mass. The surface is covered by entothelium. 
organization, from a small amount up to comp'ete fibrosis. A slight or moderate grade of mononuclear cellular infiltration is quite constantly present at the base of the vegetation. This may be present elsewhere in the valve, but usually is not.

The more organized verrucæ very often revealed a whorllike arrangement of the newly formed connective tissue and some of the completely organized verrcuæ are made up of very dense fibrous tissue, with few flattened, densely staining nuclei. Areas of hyalin (possibly thrombus) are found in some of the verrucx. Microscopically the structure of the valves is seen to be made up of dense, irregularly arranged fibrous tissue. The dense fibers of this tissue are, in general, parallel to the valve surfaces, but a wavy or even a whorllike arrangement of the fibers is often present. These whorls are found with special frequency in flattened knoblike projections of the valves near the verrucæ, and seem to be the result of the manner of organization of the verrucaæ. The central portion of the valve often contains areas of hyaline degeneration.

The cracks mentioned above are bare of endothelium, which stops at the edge. The base is made up of the fibrous tissue of the valve, with a layer of superficial degeneration, and here and there, small bits of hyaline thrombus. A considerable degree of calcareous deposit is usually present along the edge and in the base of the crack.

Nonbacterial Endocardial Vegetations in Congenitally Abnormal Hearts.-It is recognized that "endocarditis" commonly develops on valves of congenitally abnormal hearts. Necropsies have been performed in many of these cases and the cardiac abnormalities and gross appearance of the valves have been described carefully. Unfortunately, the microscopic structure of the valve lesions has seldom been studied. Bacteriologic investigations either have not been done at all, or have been unsatisfactory. Sufficient care has not been taken to rule out postmortem invaders of the heart's blood when positive postmortem bacterial cultures were obtained. Very few cases were studied clinically by means of blood cultures. Many of the important and most often quoted cases came to necropsy previous to, or during the early years of, the development of the science of bacteriology.

Nevertheless, quite a number of cases of "congenital heart disease" are recorded in the literature in which it has been proved that a superimposed acute or subacute bacterial endocarditis occurred. The heart valves have usually shown a chronic thickening and bacterial vegetative process. This fact directs attention to well known observations which are of importance. One is, that the valves of congenitally abnormal hearts are prone to become thickened and fibrosed. The other is that these compromised valves are susceptible to bacterial infections, just as is the case with all chronically diseased heart valves. 


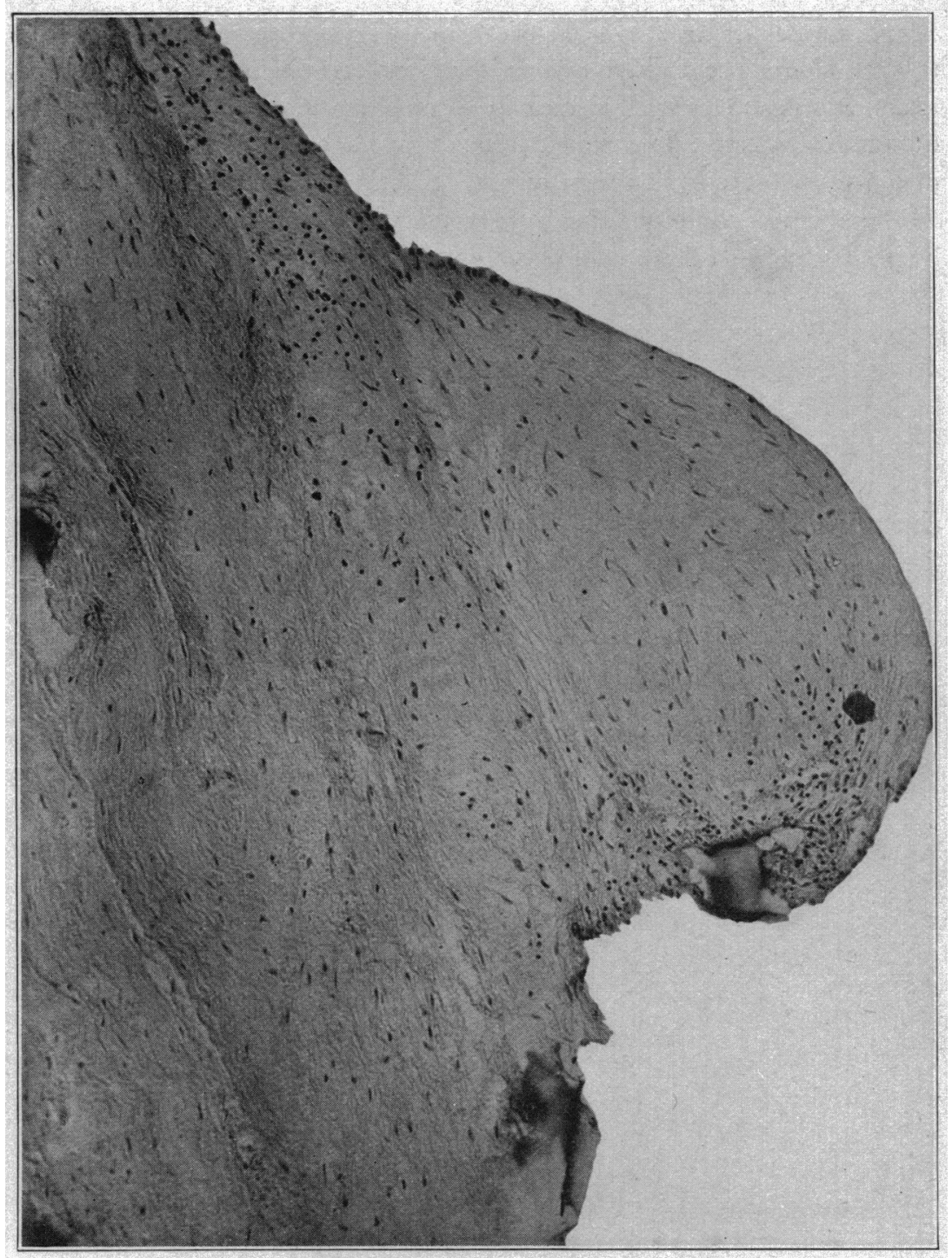

Fig. 6.-Verruca on mitral valve in a case of chronic cardiovalvular disease. Organization is almost complete, only two small unorganized areas of hyaline thrombus remain. The newly formed connective tissue has a whorllike arrangement. The surface is almost completely covered by endothelium. The vegetation is flattened and almost completely incorporated into the valve. 
Attention can now be directed to certain organic changes in congenitally abnormal hearts and also to some personal observations of these changes.

A number of cases are on record in which endocardial thickening, or thickening of the intima of the large arteries which arise from the heart, has been observed at situations where abnormalities in the course of the blood stream through the heart have caused this stream to impinge on the endocardium or intima, or to put unusual strain on it. These thickenings have also occurred at places where slowing of the blood stream, or eddies in it, have occurred. Bacterial endocarditis has also been found at these situations. Illustrations of this are lesions (bacterial or nonbacterial) in the pulmonary artery opposite an open ductus arteriosus where the blood has impinged, or around the pulmonary opening of the ductus where the stream has been slowed and thrown into eddies.

In addition, I have had the opportunity to study several congenitally abnormal hearts where nonbacterial vegetative lesions were present on the valves. ${ }^{3}$ To avoid repetition of what has gone before-the lesions bear a striking resemblance macroscopically and microscopically to the verrucæ of rheumatic endocarditis, terminal endocarditis and those observed on chronically diseased valves.

PRELIMINARY SUMMARY

The nonbacterial vegetations on the heart valves which have been described are formed of small thrombi on the valve. These lesions are verrucous rheumatic endocarditis, terminal verrucous "endocarditis" verrucæ on chronically diseased valves, and nonbacterial vegetations on the valves of congenitally abnormal hearts. It is believed that the same conditions which govern thrombus formation in blood vessels govern the formation of a thrombus on a heart valve. The underlying factors in thrombus formation are not understood perfectly, but a great deal of investigation of the condition has been made and the summation of our knowledge of the subject is best given in the conclusions arrived at by Aschoff : ${ }^{4}$

So we see from all these experiments that the slowing of the blood stream and the alteration of the blood elements themselves, especially alterations of the platelets, are the chief factors in the production, not only of the static, but of toxic thrombosis, so far as we are concerned with thrombus formation in the flowing blood stream. In static and similar types of thrombi the slowing of the blood stream is of primary importance, while for the toxic varieties the changes in the blood elements have the dominating influence.

3. One of these cases has been quoted in Dr. Abbot's article on Congenital Heart Disease, in Osler's System of Medicine.

4. Aschoff, L.; von Beck, B., and de la Camp, O.: Beiträge zur Thrombosefrage, Leipzig, Verlag von F. E. W. Vogel, 1912. 


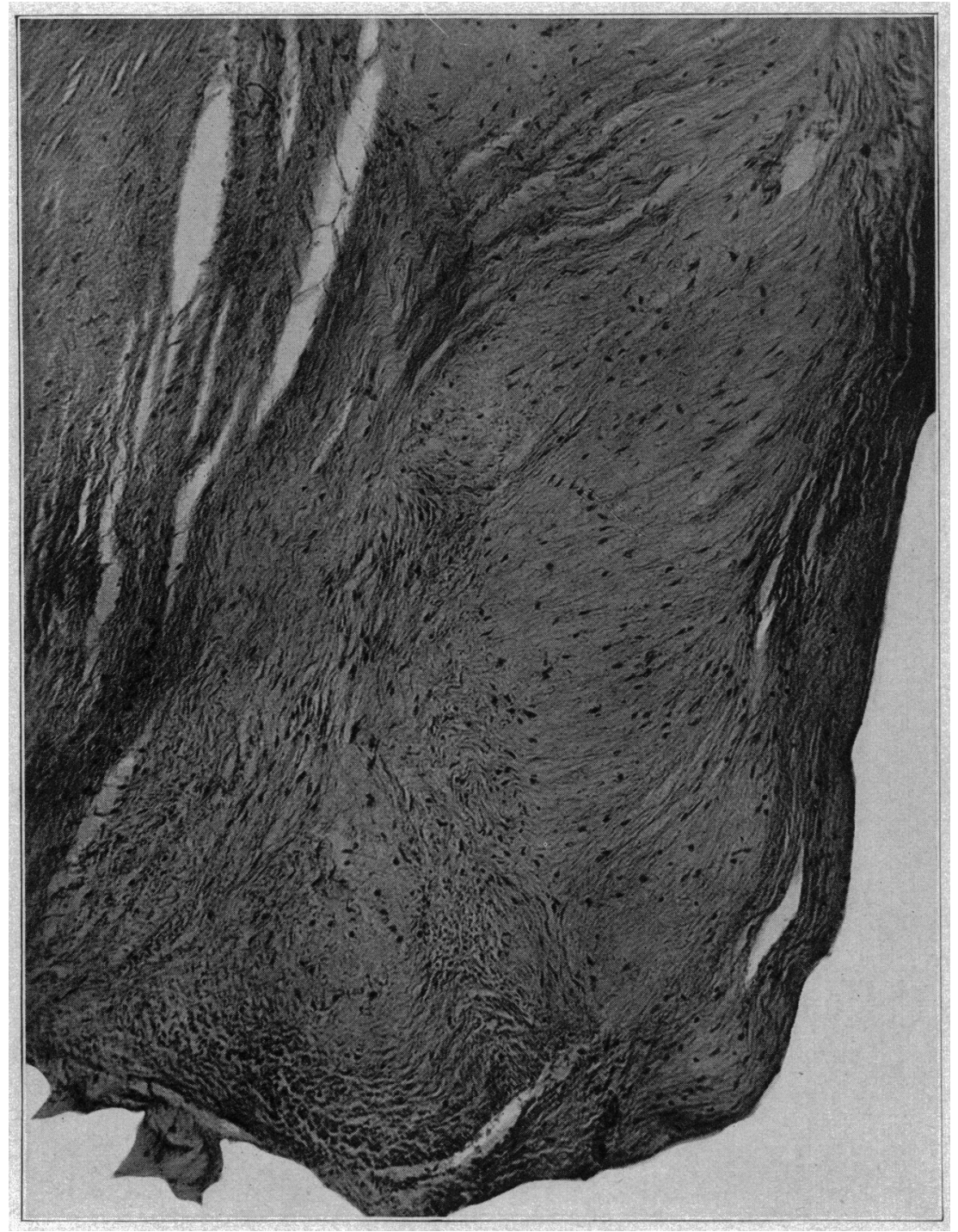

Fig. 7.--Chronic cardionaludar discase. Whorls oceur in the fibrom tissue of the aurtic value. 
The different types of chronic cardiovalvular disease and aseptic vegetations will be taken up separately, and a theory of the cause, development and end result will be advanced.

PROPOSED EXPLANATION OF MECHANISM OF DEVELOPMENT OF DIFFERENT TYPES OF CHRONIC CARDIOVALVULAR LESIONS

Verrucous Rheumatic Endocarditis.-There is sufficient evidence of inflammation in the heart valve first, to term this process "endocarditis" and, second, to believe that the vegetations develop secondary to an injury to the valve, caused by the infectious agent of rheumatic fever, which is at present unknown. Undoubtedly, fibrosis develops in the valve as a result of the inflammatory process. The inflammation is only moderate in degree and the amount of scar tissue which forms diffusely in the valve is only moderate in amount. The valve is made slightly thicker and less elastic as a result of these changes. The verrucæ become organized, then converted into fibrous tissue, and this also adds to the irregularity and loss of resiliency of the valve. Such a valve is less resistant to the strain which it must undergo in opening and shutting many times a minute and in withstanding the intracardiac pressure during the heart beat. Its lessened elasticity will cause it to open and close somewhat more slowly than normally and this will, therefore, cause slight slowing of the blood stream past the valve, and possibly, whirls or eddies in the blood stream. These two changes in the blood stream are conducive to thrombus formation. It is also conceivable that some unusual strain on the heart, and, therefore, on the somewhat compromised valve, might cause a minute injury to the valve, such as a microscopic tear in its endothelial covering. In the presence of a slowed blood stream this microscopic surface lesion would tend to add another factor toward inducing a minute thrombus, i. e., a verrucous vegetation, to form on the valve. The subsequent organization and fibrosis of this vegetation would cause further thickening and fibrosis of the valve. This would complete a vicious cycle consisting of recurring minute thrombi on the valve, very gradual thickening, with increasing susceptibility to further thrombi until a much deformed valve would result. During the process of the slow development of this valve defect, extending over many years, the valve and heart apparently might be performing their function in a satisfactory manner and no symptoms or physical signs be evident. Finally, when a seriously defective valve has developed the efficiency of the myocardium will become impaired and both symptoms and signs of chronic cardiovalvular disease will be manifested.

It is well known that recurrent attacks of acute rheumatic fever are prone to occur, and often these recurrences each add marked insult to the already damaged heart valves and hasten the development of a 


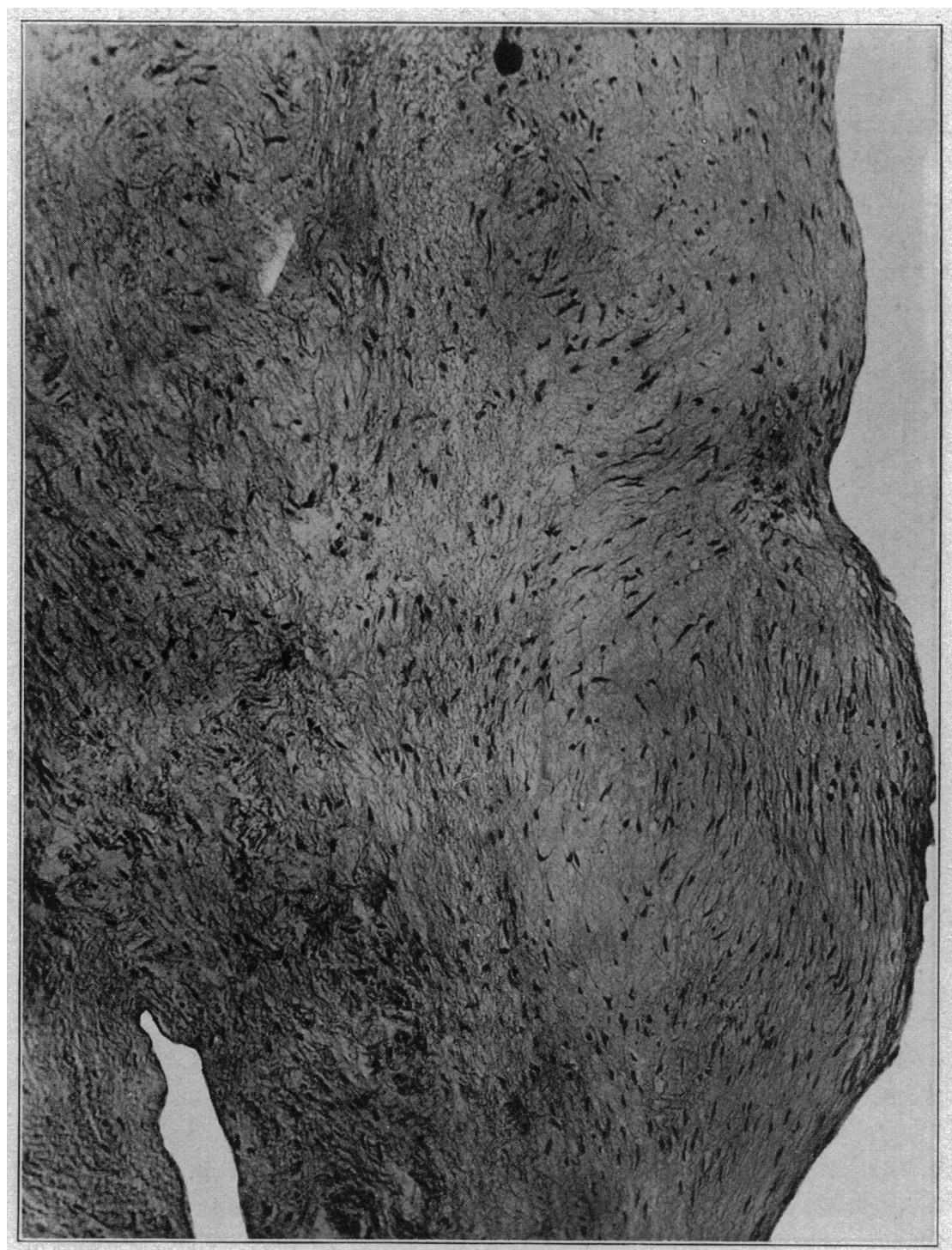

Fig. 8.-Chronic cardiovalunlar disease: mitral valve. Two, low, rounded projections of surface with whorllike arrangement of connective tissue of value heneath cach projection. 
valvular defect. We must note that repeated rheumatic inflammations of the valves are undoubtedly sufficient, without any other agency, to produce even the severest grades of valvular disease. It is, therefore, not necessary after repeated attacks of rheumatic fever have occurred, to hypothecate additional factors for causing the progress of sclerosis in the heart valves. The surface lesions in cases of acute rheumatic endocarditis, however, present so many points of similarity to lesions on sclerosed valves, which are not rheumatic in orgin, that this similarity suggested the idea of the possible significance, cause and effect of all verrucous-like, nonbacterial vegetations in the development of chronic cardiovalvular disease.

It must be recalled that an appreciable number of cases of chronic cardiovalvular disease occur in adults who have a history of only a single attack of acute rheumatic fever occurring in childhood or early life. These chronic valve lesions are attributed by clinicians to the previous attack of rheumatic fever. The explanation has not been given of how the single trauma to the heart valves long before, causing no symptoms for many years, may finally be the cause of marked valvular defects and their consequences. One attack of acute rheumatic endocarditis produces a comparatively slight valvular lesion. This may give rise to no immediate symptoms or heart murmur. It is evident that the valve defect, which is the final stage of the process, has developed slowly. The cases under discussion give no history of subsequent attacks of acute rheumatic fever or other infectious diseases to account for the development of the severe valve lesion. The explanation given here of recurring, minute verrucæ, always followed by fibrosis, would satisfactorily account for the progressive change from a slightly damaged valve to a markedly damaged one years later.

Verruca in Chronic Nonbacterial, Nonrheumatic Cardiovalvular Disease.-These lesions must have some significance, and some effect. Theoretic considerations, quite similar to those already stated, might also apply here. Some general toxic or some distant infectious process might result in a primary trauma to a heart valve, such as bacterial toxins from a serious pneumonia, repeated attacks of tonsillitis, the virus of scarlet fever, etc. Thickening of the valve follows, and these thickened valves have been found to be free from bacteria. Thus, the process of valve thickening can be regarded as nonbacterial in orgin. The thickened valve is more susceptible to both normal and unusual strain. Microscopic lesions form, followed by verrucx, and these, in turn, by fibrosis. Following this, the sequence of progressive changes may occur in the same manner as has been described as possible after a single attack of acute rheumatic fever. This may eventually produce marked stenosis with a shelflike formation at the line of valve closure. 
Cardiovalvular Lesions in Atherosclerosis.--Fibrosed, thickened and stenosed valves, found in general atherosclerosis can be explained similarly. The unusual amount of calcareous deposit in these cases is undoubtedly part of the process of atherosclerosis, probably initiating the valvular lesion and undoubtedly contributing markedly to its progression.

Aseptic Endocarditis and Chronic Cardiovalvular Disease in Congenitally Abnormal Hearts.-Congenitally abnormal hearts, which at necropsy show thickening and fibrosis of their valves, usually show no inflammatory reaction in the valves. The thickening is similar to that found in chronic valvular defects in aduits. This does not include those with a superimposed bacterial endocarditis.

It must be granted that abnormal openings in a heart, or stenosis of its valves, result in one or several occurrences, such as, slowing of the circulation in the heart, whirls or eddies in the circulation, direct impinging of the blood stream on abnormal endothelial sites, etc.

A heart of this type is working under a strain. This is exemplified clinically by evidence of cardiac insufficiency occurring more easily after muscular activity in persons who have congenitally abnormal hearts than in normal persons. Poor or retarcled physical development in children with congenital hearts is well known, and is another evidence of the inefficient cardiac mechanism. Such a heart and its valves are undoubtedly abnormally susceptible to a strain.

One can only consider hypothetically the possible result of this susceptibility to strain and of the abnormal course of intracardiac circulation and attempt to correlate it with the findings in other similar conditions. A few data of the effect of abnormal circulation and slowing of the circulation in the more common types can be brought forward before passing on to the theoretic considerations. A number of cases are on record in which, in aortic insufficiency, valvelike structures similar to the valves in the veins, developed on the interventricular septum below the aortic valves. This is the region where the regurgitated blood passes back through the aortic ring and impinges on the septum. Also, thrombus formation, due to slowing of the circulation because of chronic cardiovalvular clisease is not uncommon in the auricular appendages. These appendages, because of their location, are more likely than any other structure to accommodate a slowed circulation or eddies in the circulation. These lesions are marked evidence of the effect of abnormal intracarliac circulation and slowing of the blood stream.

It would seem, then, hypothetically, that the following is possible: Congenital cardiac anomalies may catuse the valves to be under an unusual strain from time to time. Minute, endothelial breaks, cracks, or damage may result. After these changes have occurred, fibrosed 
valves may develop gradually in the manner and by the mechanism already described. Even larger vegetations may occur than those found in simple chronic valve disease. The reason may be that in congenital hearts the circulation is more abnormal, slower, and conducive to the development of larger vegetations.

Terminal Verrucous Endocarditis.-These lesions can be considered to give the clue to the significance of similar valve lesions found in other conditions, and described above. The verruca, which are terminal, are composed also of a hyaline thrombus and would seem to be induced both by slowness of the circulation, as vitality diminishes and death approaches, and, in some cases, by an increased coagulability of the blood. Death usually occurs before these thrombi can become organized.

\section{SUM MARY}

There is no satisfactory explanation as to why a slight nonbacterial clamage to a heart valve during childhood gradually progresses and years later results in a severe chronic nonbacterial cardiovalvular lesion. The etiology of many of these chronic lesions is attributed by some observers to the direct action of bacteria. This is undoubtedly erroneous. They are entirely different from the lesions of bacterial endocarditis. They, however, may be caused indirectly by bacteria through the effect of toxins.

The cause of the chronic valvular lesion in a case such as the following is not at the present time explained. There is either no history of an original insult to the heart valve, or there is a history of a single insult in childhood or youth. No subsequent symptoms of cardiac disease developed, and also, no heart murmurs, or only very slight murmurs. For many years there are no symptoms or signs of a lesion of the heart valve. Then, either slight or mild cardiac symptoms are manifested, at which time a heart murmur is found, or, no heart symptoms being present, the murmur is discovered during a routine physical examination. After this there is a more rapid progression of the heart lesion and the heart symptoms.

The question which suggests itself is, why has the lesion become manifest at this time, and what has occurred to the heart valve in the interim between the original insult to the valve and the later development of the valve lesion? The following argument is presented as a possible explanation of what has occurred: There was an original insult from one or more of the following diseases: scarlet fever, measles, tonsillitis, pneumonia, etc. The best evidence indicates that the slight cardiovalvular injury which occurs during these diseases is not caused by a deposit of bacteria in or on the valve. These lesions are, therefore, nonbacterial. (The occasional case of frank pneumococcus endocarditis 
and other cases of bacterial endocarditis are not being considered here.) The nonbacterial process in the valve resulted in slight or mild fibrosis. The change in the valve was not serious enough to impair the heart function and cause heart symptoms; it may not have been even sufficient to have caused heart murmurs. This slightly damaged valve, however, did not have the resiliency, elasticity and reserve of a normal valve. The ordinary work of the heart put a strain on it. With the slight thickening of the valve a slight abnormality of the circulation over and around the valve occurred, which resulted in slight whirls or eddies, or slight slowing of the blood stream. Activities such as heavy lifting, or exercise, may have resulted in so much strain that a microscopic clamage, which would not happen normally, was inflicted on the endothelium of the valve. At the site of this damage a minute thrombus was deposited. The whirls in the circulation about the valve, or the slight slowing of the blood stream, helped in the formation of this thrombus. This thrombus is the aseptic, verrucous, endocardial lesion or vegetation described herein. This verrucous vegetation became organized, then fibrosed and incorporated in the valve, adding to its thickening and fibrosis. This process still further lessened the elasticity, resiliency, etc., of the valve and rendered it more liable to subsequent minute injuries, verruca, and the result of organization of these verrucæ. Thus, a vicious cycle is completed, each minute injury and its repair rendering the valve more susceptible to further injury.

It is a common observation that mild degrees of thickening in the heart valve are found at necropsy, which have caused no murmurs or heart symptoms during life. Therefore, it is conceivable that the progressive clange in the heart valve, which has been hypothecated above, gives rise to no heart murmurs or heart symptoms until a certain stage is reached. By that time quite a marked change in the valve is present. This markedly changed valve is especially susceptible to injury, and after this stage occurs, further progress in the lesion is more rapid. With the deformity or defect in the valve which eventually develops, the function or mechanism of the heart becomes affected and cardiac symptoms appear.

The manner in which a cardiovalvular defect eventually causes sufficient disturbance in myocardial function to precipitate signs or symptoms of myocardial insufficiency is not yet completely understood. Some subjects may go for years with a marked mitral stenosis and a perfectly compensated heart. Some subjects with no lesions of the heart valves may die from myocardial weakness due to one of many causes, such as, coronary artery disease, so-called cardiac rheumatism, toxemia of a severe infectious disease, etc.

It would seem that a valvular defect, even a serious one, if the myocardium has not also suffered damage, in many cases exists for 
a long time before the interference with the cardiac function which follows causes insufficiency of the myocardium. There is great need for investigation of the manner in which chronic valvular defects cause deleterious functional and organic changes in the myocardium.

The evidence which has been presented to explain the progress of chronic, nonbacterial cardiovalvular disease is not necessarily conclusive, and it might be considered that the hypothesis has not been proven. All stages of the progress in these valve lesions are not available for study, but the similarity of the verrucous lesions in all the conditions described strongly indicates that a simple, fundamental process is the basis of all of them. This process seems to be an attempt at repair. It is evidently an imperfect attempt, such as occurs in arterial thickening in atherosclerosis. It is, therefore, another imperfect adaptation of the protective processes of nature. The repair of the heart valve results in fibrosis, lessened resistance to strain, more damage and consequent progress of the vicious cycle which has been established. In some cases even marked stenosis of the valve may result. This is an imperfect result of repair by nature, just as an aneurysm which occurs in atherosclerosis is the result of an imperfect repair. Other instances of the result of an imperfect adaptation of nature for the purpose of repair, are thrombosis in a blood vessel and its sequels, stenosis of the coronary artery in atherosclerosis, etc.

It is hoped that these hypothetic considerations, in spite of their possible incompleteness or imperfections, may direct attention to the processes described, and if the hypothesis is not justified by subsequent observation, that it may stimulate other investigations of the cause of development and progression of chronic cardiovalvular defects. 